\title{
Laboratory Evaluation of Fiber-Modified Asphalt Mixtures Incorporating Steel Slag Aggregates
}

\author{
Adham Mohammed Alnadish ${ }^{1, *}$, Mohamad Yusri Aman ${ }^{1}$, Herda Yati Binti Katman ${ }^{2}$ \\ and Mohd Rasdan Ibrahim ${ }^{3}$
}

\footnotetext{
${ }^{1}$ Department of Civil Engineering and Built Environment, Universiti Tun Hussein Onn Malaysia, Parit Raja, 86400, Malaysia

${ }^{2}$ Department of Civil Engineering, Universiti Tenaga Nasional, Kajang, 43000, Malaysia

${ }^{3}$ Department of Civil Engineering, Universiti Malaya, Kuala Lumpur, 50603, Malaysia

*Corresponding Author: Adham Mohammed Alnadish. Email: adhmalnadish@gmail.com Received: 29 January 2021; Accepted: 21 July 2021
}

\begin{abstract}
Vigorous and continued efforts by researchers and engineers have contributed towards maintaining environmental sustainability through the utilization of waste materials in civil engineering applications as an alternative to natural sources. In this study, granite aggregates in asphaltic mixes were replaced by electric arc furnace (EAF) steel slag aggregates with different proportions to identify the best combination in terms of superior performance. Asphalt mixtures showing the best performance were further reinforced with polyvinyl alcohol (PVA), acrylic, and polyester fibers at the dosages of $0.05 \%$, $0.15 \%$, and $0.3 \%$ by weight of the aggregates. The performance tests of this study were resilient modulus, moisture susceptibility, and indirect tensile fatigue cracking test. The findings of this study revealed that the asphalt mixtures containing coarse steel slag aggregate exhibited the best performance in comparison with the other substitutions. Moreover, the reinforced asphalt mixtures with synthetic fibers at the content of $0.05 \%$ exhibited an almost comparable performance to the unreinforced asphalt mixtures. Modifying the asphalt mixtures with PVA, acrylic, and polyester fibers at the proportion of $0.15 \%$ have improved the fatigue cracking resistance by $41.13 \%, 29.87 \%$, and $18.97 \%$, respectively. Also, the fiber-modified asphalt mixtures with PVA, acrylic, and polyester have enhanced the fatigue cracking resistance by about $57 \%, 44 \%$, and $39 \%$, respectively. The results of the resilient modulus demonstrated that as the fiber content increase, the resilient modulus of the reinforced asphalt mixtures decreases. Therefore, introducing synthetic fibers at the content of $0.3 \%$ has slightly decreased the resilient modulus in comparison with unreinforced mixtures. On the other hand, the results of the mechanisticempirical pavement design showed that the reinforced asphalt mixes with a high content of synthetic fibers have shown lower service life than the control mixes due to the low resilient modulus. On the contrary, based on the laboratory results, the asphalt mixes incorporating PVA, acrylic, and polyester fibers
\end{abstract}


at the proportion of $0.15 \%$ have shown the potential to reduce the thickness of the asphalt layer by about $14.9 \%, 11.80 \%$, and $8.70 \%$, respectively.

Keywords: Steel slag aggregate; polyvinyl alcohol fiber; acrylic fiber; polyester fiber; cracking resistance; resilient modulus

\section{Introduction}

Management and getting rid of waste materials become a major issue in recent years due to the large quantities of waste and by-product materials generated from multiple industries. Therefore, researchers have made efforts to use industrials wastes as an alternative for natural aggregate in civil engineering applications as a strategy to ensure environmental sustainability. Steel slag aggregate is one of the common waste materials used in civil engineering applications because of its characteristic properties that improve the mechanical properties of the asphalt mixtures. The utilization of steel slag aggregates in asphalt mixtures has become the focus of researchers' attention due to the superior performance of the asphalt mixtures incorporating steel slag aggregates. Several studies have assessed the asphalt mixtures incorporating steel slag aggregates. Behnood et al. [1] investigated electric arc furnace (EAF) coarse steel slag aggregate in stone mastic asphalt (SMA). The study concluded that the asphalt mixes containing steel slag aggregates have improved the Marshal Stability, stiffness modulus, and indirect tensile strength. Also, Ziari et al. [2] conducted a study on using steel slag as a coarse aggregate. The results of the study showed that the asphalt mixtures containing steel slag aggregates exhibited better Marshal Stability, indirect tensile strength, and higher fatigue life than the control mixtures. This was attributed to the angularity of the steel slag, which improves the interlocking between the particles. Pasetto et al. [3,4] conducted several evaluations on the performance of asphalt mixes containing steel slag aggregate. The researchers observed that the mixtures containing steel slag aggregates at the proportion of $90 \%$ have shown better resistance to fatigue cracking in comparison with the control mixtures and the other proportions. Additionally, the researchers observed that the mixtures incorporating $90 \%$ of steel slag aggregate exhibited better TSR and resistance to the tensile strength than the control mixtures. The authors attributed this enhancement to the high content of the asphalt binder. Similarly, Ahmedzade et al. [5] evaluated the asphalt mixtures containing steel slag aggregate as a coarse aggregate. According to their findings, the asphalt mixtures containing coarse steel slag aggregate exhibited higher resistance to cracking, higher stiffens modulus, and higher resistance to moisture damage as compared to the control mixtures. Arabani et al. [6] evaluated the resistance of the asphalt mixtures containing coarse steel slag aggregates to cracking using the test of indirect tensile fatigue test (ITFT). The study demonstrated that the mixtures composing coarse steel slag aggregate showed the highest resistance to cracking. Likewise, Kavussi et al. [7] investigated the mixtures incorporating steel slag aggregate by the four-point fatigue test. The researchers found that the mixtures containing coarse steel slag aggregate exhibited better fatigue life than the control mixes. Wen et al. [8] observed that the asphalt mixtures containing EAF steel slag aggregate gave similar results in terms of tensile strength ratio (TSR) in comparison with the control mixtures. Ameri et al. [9] and Hesami et al. [10] however, indicated that the hot asphalt mixtures composing coarse steel slag aggregate have slightly decreased TSR in comparison with the control mixtures.

Nevertheless, one of the main problems associated with utilizing steel slag aggregate in asphalt mixtures is its high density, which increases the cost of transportation. In this regard, enhancing the mechanical properties of the asphalt mixtures by modifying the asphalt mixtures with certain 
additives may allow the thickness of the asphalt layer to be decreased. Thus, transportation and construction costs are minimized. Modifying the binder with the additives of polymer and copolymers has been documented as a successful strategy regarding improving the properties of the binder, which in turn enhances the performance of the asphalt mixes. Otherwise, modifying the binder with polymer and copolymer additives produce asphalt mixtures susceptible to aging [11-13]. Consequently, the researchers are tending to decrease the factors that adversely affect the bitumen through modifying the asphalt mixtures. Accordingly, reinforcing the asphalt mixtures with synthetic fibers is classified as a successful strategy in terms of extending the service of the asphalt layer due to the abilities of the fibers to enhance the resistance of the asphalt mixtures to cracking, tensile strength, and permanent deformation. Moreover, reinforcing the asphalt mixtures with synthetic fibers is documented as an effective practice in terms of producing asphalt mixtures with superior performance. The high performance of the fiber-modified asphalt mixtures prompted researchers to use a variety of synthetic fibers as a contribution to improve the efficiency and lifespan of the asphalt layer. Polypropylene (PP) fiber is a type of synthetic fiber, which is a by-product of petroleum production. PP fibers have been used in asphalt mixtures to enhance the properties of the mixtures for many decades. In a study carried out by Tapkin [14] the reinforced asphalt mixtures with PP fiber have enhanced the Marshal stability and decreased flow of the mixtures. Likewise, the resistance of the mixtures to cracking has been improved compared to the control mixtures. In similar content, Abtahi et al. [15] have evaluated the asphalt mixtures incorporating PP fiber. Their conclusions have shown that the reinforced mixtures with polypropylene (PP) with the length of $3 \mathrm{~mm}$ and the dosage of $0.3 \%$ by weight of the mix enhanced the Marshal Properties and dynamic creep of the mixtures. Klinsky et al. [16] studied the effect of adding PP fiber into asphalt mixtures with a length of $6 \mathrm{~mm}$ and a dosage of $0.5 \%$ by volume of the sample. The results of the study concluded that adding PP fibers had enhanced the properties of the mixtures concerning of Marshal Stability and indirect tensile strength. Although, the researchers indicated that the main disadvantage of using polypropylene fibers is its low melting point $\left(160^{\circ} \mathrm{C}\right)$, and thus PP fibers should be introduced to the mixtures by the wet process, and this has a negative impact on the storage stability of the binder. On the other hand, polyester fibers are the common type of synthetic fiber, which is manufactured from petroleum-based products. Several studies have evaluated polyester fibers in asphalt mixes. Wu et al. [17] stated that reinforcing the asphalt mixtures with polyester fibers at the dosage of $0.3 \%$ by weight of the mix exhibited higher resistance to cracking than the unreinforced asphalt mixes. Chen et al. [18] observed that with the increase in the content of the polyester fibers from $0 \%$ to $0.35 \%$ by weight of the mix the resistance of the mixtures to moisture sensitivity and rutting has increased. Similarly, Kim et al. [19] indicated that adding polyester fiber with a length of 6 $\mathrm{mm}$ at the dosage of $1 \%$ by volume of the sample has improved the resistance of the mixture to fatigue, indirect tensile strength, and dynamic stability.

Carbon fiber is a type of synthetic fiber with its unique properties regarding its high melting point (over $1000^{\circ} \mathrm{C}$ ), high tensile strength, and high thermal conductivity. The utilization of carbon fiber has been evaluated on asphalt mixtures for many years. Jahromi et al. [20] studied the effect of adding carbon fiber in asphalt mixtures. The findings of the study showed that the reinforced mixtures with carbon fiber have no effect on the mechanical properties of the asphalt mixtures. Otherwise, the fatigue life of the reinforced asphalt mix has slightly improved. Kim et al. [19] introduced carbon fiber with a length of $6 \mathrm{~mm}$ by the dry process into dense asphalt mixtures at the dosage of $0.5 \%$ and $1 \%$ by volume of the mixture. The study stated that adding carbon fiber does not enhance the mechanical properties of the mixtures. This is because of the tangle of the fiber, and thus the fibers are not distributed well within the sample. 
The main advantage of carbon fiber is its high thermal conductivity, which enhances the thermal conductivity of the asphalt layer. Thus, the micro-cracks in the asphalt layer can be healing rapidly, if the layer subjected to microwave heating. Otherwise, the main disadvantages of carbon fibers are the high cost and high density.

Basalt fiber is another type of synthetic fiber made from fine basalt fiber. Basalt fiber is characterized by its high melting point (higher than $1000^{\circ} \mathrm{C}$ ) and high tensile strength $(4500$ $\mathrm{MPa}$ ). The utilization of basalt fiber in the asphalt mixture has been performed in many studies. Morova [21] documented that adding basalt fiber with a length of $6 \mathrm{~mm}$ to the denes asphalt mixture by the dry process at the optimum content of $5 \mathrm{~kg} / \mathrm{ton}$ has increased Marshal Properties of the mixtures compared to the control mixtures. Xiong et al. [22] investigated the ability of the basalt fiber to improve the mechanical properties of the mixtures. The results of the study showed that introducing basalt fibers with a length of $6 \mathrm{~mm}$ by the dry process at the optimum content of $0.3 \%$ has enhanced the resistance of the mixtures to rutting as well as Marshal Properties have enhanced. On the other hand, basalt fiber is brittle which may damage during the compaction process in situ or by the axles loads, if the basalt fiber used in the surface layer. Thus, basalt fiber is suitable for the binder course. The high density of the basalt fiber $\left(2.8 \mathrm{~g} / \mathrm{cm}^{3}\right)$ increases the cost of the mixture [21].

Glass fiber is a type of inorganic fiber with a high melting point and high tensile strength. Fiberglass has been used vastly to improve the properties of the asphalt mixture. Guo et al. [23] investigated the performance of the asphalt mixtures incorporating fiberglass with a length of $12 \mathrm{~mm}$ at the dosages of $0.1 \%, 0.2 \%$, and $0.3 \%$ by weight of the mix with regard to resilient modulus, fatigue resistance, and dynamic creep. The researchers found that with the increase in the dosage of fiberglass the resilient modulus, fatigue, and rutting resistance have been improved. In similar content, Fakhri et al. [24] evaluated warm mix asphalt containing RAP and $0.3 \%$ of fiberglass in terms of moisture sensitivity and rutting resistance. The study demonstrated that adding fiber to the mixtures has increased the resistance of the mixtures to moisture sensitivity and rutting resistance. In general, introducing fiberglass into asphalt mixtures increases the initial cost of the mixture, but it saves the cost of the maintenance since it extends the service life of the asphalt layer. Reciprocally, fiberglass is brittle, which may damage during the compaction process. Also, the high density of the glass fiber $\left(2.6 \mathrm{~g} / \mathrm{cm}^{3}\right)$ requires a high amount of fiber to reach the optimum content as well as to perform well [25].

Nylon fiber is a type of synthetic polymers. Various studies have shown that reinforcing the asphalt mixtures with nylon fiber heightens the efficiency of properties of the asphalt mixtures. Lee et al. [26] added nylon fiber by the dry process at the dosages of $0.25 \%, 0.5 \%$, and $1 \%$ by volume of the mixtures with different lengths of 6 and $12 \mathrm{~mm}$ in order to investigate the resistance of the reinforced mixtures to fracture energy. The results elucidated that the optimum content and length were $1 \%$ and $12 \mathrm{~mm}$. At the optimum content and the optimum length, the fracture energy has increased by about $85 \%$. In another study conducted by Kim et al. [19] nylon fiber with a length of $12 \mathrm{~mm}$ was added into mixtures by the dry process at the content of $0.5 \%$ and $1 \%$ by volume of the mixtures. The mixtures were performed by indirect tensile strength, wheel tracking test, and flexural fatigue. The mixtures containing $1 \%$ of nylon fiber exhibited the best performance in comparison with other proportions and the control mixtures. The indirect tensile strength, dynamic stability, and fatigue have enhanced by $12 \%, 35 \%$, and $20 \%$, respectively. Acrylic fiber is a type of synthetic fiber made from polyacrylonitrile. A number of studies have evaluated the capability of acrylic fiber to improve the mechanical properties of asphalt mixtures. MorenoNavarro et al. [27] found that adding acrylic fiber at the proportion of $0.3 \%$ by weight of the mix 
has improved the resistance of the asphalt mixtures to permanent deformation. Wang et al. [28] investigated the cracking resistance of the fiber-modified asphalt mixtures with acrylic fiber at the dosages of $0.15 \%, 0.3 \%$, and $0.45 \%$ by weight of the aggregates. The researchers found that adding acrylic fiber at the percentage of $0.3 \%$ exhibited the best resistance to cracking. Whereas reinforcing of the asphalt mixtures with acrylic fiber at the dosage of $0.45 \%$ showed the worst resistance to cracking.

Aramid fiber is another type of synthetic fiber, which is characterized by its high melting point over $500^{\circ} \mathrm{C}$ and its high tensile strength (3800 MPa). Klinsky et al. [16] investigated adding aramid fiber mingled with polypropylene into dense-graded asphalt mixture at the content of 0.5 $\mathrm{kg} / \mathrm{ton}$. The outcomes of the study articulated that introducing aramid fiber has improved the resistance of the mixtures to permanent deformation by around 16 times compared to the neat mixtures. Also, the reinforced asphalt mixtures with the aramid fiber and polypropylene exhibited better resistance to flow number than the reference mixtures by 3 times. In another study, conduct by Alnadish et al. [29] the coated aramid fibers with Sasbobit with a length of $18 \mathrm{~mm}$ at different dosages i.e., $0.02 \%, 0.05 \%, 0.1 \%$, and $0.3 \%$ have been introduced to the dense-graded asphalt mixtures. The results showed that introducing aramid fiber at the dosage of $0.05 \%$ by weight of the aggregates had improved the permanent deformation and the resilient modulus of the asphalt mixes. On other hand, Alnadish et al. [30] noted that modifying the asphalt mixtures with polyvinyl alcohol fiber at the content of $0.05 \%$ by the aggregates weight had improved the mixture's resistance to permanent deformation and revealed the ability to decrease the thickness of the asphalt layer.

Furthermore, Alnadish et al. [31] studied the effect of the elastic behavior on the performance of the reinforced asphalt mixes composed of coarse steel slag aggregates, PVA, polyester, and acrylic at the proportion of $0.3 \%$ by weight of the aggregates. The findings of the study demonstrated that the low frequencies of the applied loads negatively affected the resistance of the asphalt mixes to cracking due to the elastic behavior. Alnadish et al. [32] conducted laboratory characterization of reinforced asphalt mixes incorporated coarse steel slag aggregates and reinforced with PVA, polyester, and acrylic at the content of $0.3 \%$ by weight of the aggregates subjected to long term oven aging. The results of the study revealed that the fibers have successfully decreased the effect of aging on the performance of the modified asphalt mixes with synthetic fibers.

In this study, the suitability of using steel slag aggregates in asphalt mixtures was investigated. The natural aggregates were substituted with different proportions of steel slag aggregates i.e., coarse steel slag, fine steel slag, and $100 \%$ of steel slag aggregates to identify the appropriate replacement in terms of superior performance. Thereafter, asphalt mixtures showing the best performance were further reinforced with polyvinyl alcohol (PVA), acrylic, and polyester fibers. The synthetic fibers of PVA, acrylic, and polyester were selected for this study due to their low density, low cost, and better elasticity in comparison with the other fibers such as basalt, glass, aramid, and carbon. The asphalt mixtures were reinforced with different proportions of synthetic fibers i.e., $0.05 \%, 0.15 \%$, and $0.3 \%$ by weight of the aggregates to introduce a better understanding for the effect of the fiber content on the performance of the asphalt mixes. The performance of the reinforced asphalt mixes was evaluated in terms of resilient modulus, moisture susceptibility, and cracking resistance. Also, statistical analysis was conducted to study the influence of the fiber's proportions on the performance of the fiber-modified asphalt mixtures. Furthermore, this study focused on the mechanistic-empirical design of the reinforced asphalt mixtures to assess the effect of the flexibility of the modified asphalt mixtures with different dosages of synthetic 
fibers on the outputs of mechanistic-empirical pavement design. Additionally, the results of the performance tests were utilized as a contribution in terms of assessing the possibility of decreasing the thickness and extending the lifespan of asphalt layer modified with synthetic fibers.

\section{Materials and Methods}

\subsection{Materials}

The dense-graded asphalt mixtures were prepared with a binder of $80 / 100$ penetration grade, which is produced by PETRONAS (Kuala Lumpur, Malaysia). The physical properties of the binder are summarized in Tab. 1. The crushed granite and electric arc furnace (EAF) steel slag aggregates were employed in this study. The EAF steel slag and granite aggregate were obtained from NCL chemicals Ltd chemical products, Singapore and Hanson Quarry, Batu Pahat, Malaysia, respectively. The properties of the steel slag and granite aggregates are listed in Tab. 2. The synthetic fibers of polyvinyl alcohol (PVA), acrylic, and polyester were used in this study. The synthetic fibers were supplied by Taian Tongban Fiber Co., Ltd (Shandong, China). Fig. 1 shows the synthetic fibers. The mechanical and physical properties of the synthetic fibers are listed in Tab. 3. The finer gradation of the nominal maximum size aggregate of $12.5 \mathrm{~mm}$ was adopted in order to decrease the effect of the porosity of the steel slag aggregates on the optimum bitumen content. The gradation of the nominal maximum size aggregates $12.5 \mathrm{~mm}$ is shown in Fig. 2 .

Table 1: The physical properties of the binder

\begin{tabular}{lll}
\hline Properties & Result & Standard \\
\hline Bitumen grade & $80 / 100$ & - \\
Penetration @ 25 $\mathrm{C}(0.1 \mathrm{~mm})$ & 93 & ASTM D5 [33] \\
Softening Point $\left({ }^{\circ} \mathrm{C}\right)$ & 45 & ASTM D36 [34] \\
Ductility@ $25^{\circ} \mathrm{C}(\mathrm{cm})$ & 141 & ASTM D113 [35] \\
Penetration Index (PI) & -1 & - \\
Viscosity @ $135^{\circ} \mathrm{C}(\mathrm{mPa} . \mathrm{s})$ & 487 & - \\
Viscosity@ $165^{\circ} \mathrm{C}(\mathrm{mPa} . \mathrm{s})$ & 144 & ASTM D4402 [36] \\
Mixing temperature & $160^{\circ} \mathrm{C}$ & ASTM D2493 [37] \\
Compaction temperature & $150{ }^{\circ} \mathrm{C}$ & ASTM D2493 [37] \\
\hline
\end{tabular}

Table 2: The physical properties of the steel slag and granite aggregates

\begin{tabular}{lllll}
\hline Properties & \multicolumn{2}{l}{ Result } & \multirow{2}{l}{ Specification } & Standard \\
\cline { 2 - 3 } & Granite & Steel slag & & \\
\hline Loss angeles abrasion & 22 & 17.80 & $\leq 25 \%$ & ASTM C131 [38] \\
Aggregate crushing value $(\%)$ & 25 & 22.60 & $\leq 25 \%$ & IS: 2386 (Part IV) [39] \\
Bulk S.G. $\left(\mathrm{g} / \mathrm{cm}^{3}\right)$ & 2.63 & 3.22 & N/A & ASTM C127 [40] \\
Water absorption $(\%)$ & 0.84 & 2.75 & $\leq 3 \%$ & ASTM C127 \\
Flat and elongated $(\%)$ & 8.40 & 3.90 & $\leq 10 \%$ & ASTM D4791 [41] \\
Angularity $(\%)$ & 84 & 95 & $\geq 80 \%$ & ASTM D5821 [42] \\
Free CaO content $(\%)$ & - & 1.17 & $\leq 4 \%$ & - \\
\hline
\end{tabular}




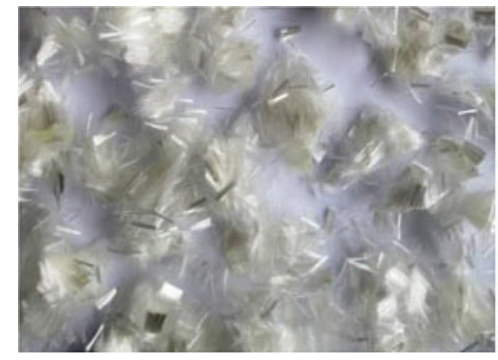

(a)

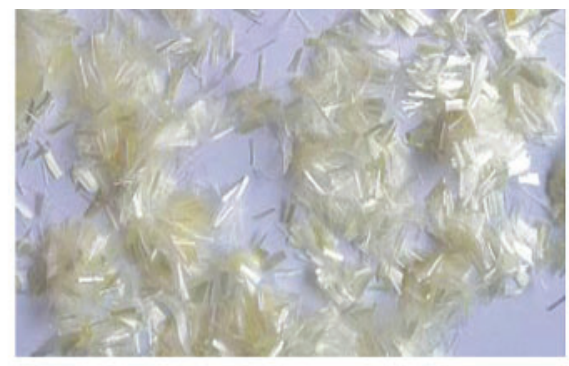

(b)

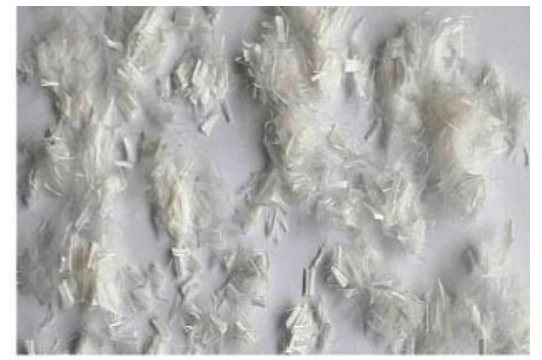

(c)

Figure 1: The synthetic fibers: (a) Polyvinyl alcohol fiber (PVA); (b) Acrylic fiber; (c) Polyester fiber

Table 3: The physical and mechanical properties of the synthetic fibers

\begin{tabular}{llll}
\hline Physical properties & Polyvinyl alcohol (PVA) & Acrylic & Polyester \\
\hline Density $\left(\mathrm{g} / \mathrm{cm}^{3}\right)$ & 1.29 & 1.17 & 1.38 \\
Tensile strength $(\mathrm{MPa})$ & $>1200$ & $>700$ & $>500$ \\
Young's modulus $(\mathrm{GPa})$ & $>20$ & $>28$ & $>7$ \\
Melting Point $\left({ }^{\circ} \mathrm{C}\right)$ & $>200$ & $>230$ & $>240$ \\
Color & Light yellow & Yellow & White \\
Length $(\mathrm{mm})$ & 6 & 6 & 6 \\
Diameter $(\mu \mathrm{m})$ & $10-20$ & $10-25$ & $10-25$ \\
\hline
\end{tabular}

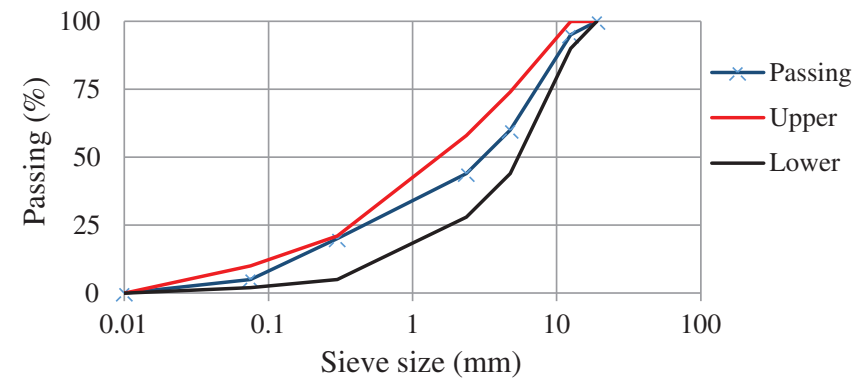

Figure 2: The finer gradation of the nominal maximum size aggregate of $12.5 \mathrm{~mm}$

\subsection{Preparation of the Samples}

In this study, granite aggregates were substituted by steel slag aggregate i.e., coarse steel slag, fine steel slag, and $100 \%$ of steel slag aggregates to determine the best combination of steel slag aggregates. Steel slag aggregate was introduced to the mixtures by volume due to its high density. Thereafter, the asphalt mixtures that containing the optimal replacement of steel slag aggregates were reinforced with the synthetic fibers of PVA, acrylic, and polyester at the proportions of $0.05 \%, 0.15, \%$ and $0.3 \%$ by weight of the aggregates, respectively. In this study, substituting the coarse granite aggregates with coarse steel slag aggregates was the optimal replacement. The reinforced asphalt mixes with the synthetic fibers at the proportions of $0.05 \%, 0.15 \%$, and $0.3 \%$ 
by weight of the aggregates were coded as Mix1, Mix2, and Mix2, respectively. The control asphalt mixtures that contain coarse steel slag aggregates were identified as Mix0. The Superpave mix design was adopted in the preparation for the specimens of the asphalt mixtures (SHRPA-407) [43]. Before mixing, the natural and steel slag aggregates were heated at the mixing temperature of $160^{\circ} \mathrm{C}$ for at least four hours. Thereafter, the aggregates and the binder were blended in an auto mixer at the mixing temperature of $160^{\circ} \mathrm{C}$. Then, the fibers were individually introduced and thoroughly blended with aggregate and the bitumen. The loose asphalt mixtures were then subjected to short-term aging at the compaction temperature of $150^{\circ} \mathrm{C}$ for at least two hours. Subsequently, the samples were compacted using a Superpave gyratory compactor (SGC, Controls Group, Milan, Italy) with 100 revolutions to compact the loose asphalt mixtures. Samples with the dimensions of $100 \pm 1 \mathrm{~mm}$ in diameter and $63 \pm 2.5 \mathrm{~mm}$ in height were produced. The optimum bitumen content of the asphalt mixes containing granite aggregates, coarse steel slag aggregates, fine steel slag aggregates, and $100 \%$ of steel slag aggregates was $4.78 \%$, $4.9 \%, 4.85 \%$, and $5.3 \%$, respectively. The density of the asphalt mixtures incorporating granite aggregates, coarse steel slag aggregates, fine steel slag aggregates, and $100 \%$ of steel slag aggregates were $2.343,2.56,2.63$, and $2.972 \mathrm{~g} / \mathrm{cm} 3$, respectively. The optimum bitumen content of the control asphalt mixes incorporating coarse steel slag aggregates was adopted as the optimum bitumen content for the fiber-modified asphalt mixes with the synthetic fibers of PVA, acrylic, and polyester at the proportions of $0.05 \%$ and $0.15 \%$. This is because introducing the fibers at the low dosages has a slight effect on the air void content. The optimum bitumen content of the fiber-modified asphalt mixes with PVA, acrylic, and polyester at the high dosage of $0.3 \%$ was $5.1 \%, 5.2 \%$, and $5.2 \%$, respectively.

\subsection{Testing Plan}

To study the positive effect of the steel slag aggregates and synthetic fibers on the performance of the asphalt mixtures different tests were carried out.

The resilient modulus of the asphalt mixtures is an important variable in the mechanisticempirical pavement design for the pavement structures. The resilient modulus test was conducted by means of a Universal Testing Machine (UTM-5P) (Inopave Group, Singapore). This test was conducted in accordance with ASTM D7369 [44]. In this test, the resilient modulus of the asphalt mixes was determined at temperatures of 25 and $40^{\circ} \mathrm{C}$. The specimens were conditioned in the environmental chamber at every testing temperature for at least four hours prior to the test. The specimens were then subjected to an indirect tensile load with a haversine wave pulse of $1000 \mathrm{~N}$. The load was applied at the frequency of $1 \mathrm{HZ}(0.1 \mathrm{~s}$ load width followed by $0.9 \mathrm{~s}$ rest period $)$. Three specimens were tested per mix.

The moisture susceptibility test was performed to study the resistance of the asphalt mixtures to moisture damage. This test was carried out following the procedures stated in AASHTO T 283 [45]. A total of 78 samples were tested to cover the scope of the test for this study. Six samples were prepared at the air voids content of $7 \% \pm 0.5 \%$ per mix. However, three samples represent the dry condition, while the other three specimens correspond to the wet condition. For the dry condition, the samples were conditioned in the climate chamber at the temperature of $25^{\circ} \mathrm{C}$ for at least two hours before applying the indirect tensile strength. For the wet condition, the specimens were subjected to saturation at the degree of $70 \%-80 \%$. Thereafter, the specimens were conditioned in a water basin at the temperature of $60^{\circ} \mathrm{C}$ for $24 \mathrm{~h}$ followed by immersing the wet specimens in a water bath at $25^{\circ} \mathrm{C}$ for at least two hours. 
The resistance of the asphalt mixtures to cracking was investigated through the test of repeated indirect tensile strength by means of Universal Testing Machine (UTM-5P) (Inopave Group, Singapore). Three specimens were tested per mix. This test was conducted in accordance with the specifications in BS EN 12697-24 Annex E [46]. In this test, the number of cycles to failure represents the fatigue life of the asphalt mixtures. The higher the number of cycles to failure, the better the resistance to cracking. The produced samples were conditioned in the climate chamber at the testing temperature of $25^{\circ} \mathrm{C}$ for at least four hours. Thereafter, the specimens were subjected to a stress of $500 \mathrm{kPa}$. The wave of the applied stress was haversine with the width load of $100 \mathrm{~ms}$ followed by the rest period of $400 \mathrm{~ms}$.

\section{Results and Discussion}

\subsection{Performance Tests Results of the Unreinforced Asphalt Mixtures}

This section presents the results of the performance tests of the unreinforced asphalt mixtures.

\subsubsection{Resilient Modulus of the Unreinforced Asphalt Mixtures}

The results of the resilient modulus are utilized as indication for the performance of the asphalt mixtures. The higher resilient modulus at $25^{\circ} \mathrm{C}$ implies the better resistance to cracking. Also, the higher resilient modulus at $40^{\circ} \mathrm{C}$, the lower the permanent deformation. Fig. 3 illustrates the resilient modulus at 25 and $40^{\circ} \mathrm{C}$ of the asphalt mixtures containing natural aggregate (granite), coarse steel slag, fine steel slag, steel slag as a fine and coarse aggregate, respectively. As shown in Fig. 3, the asphalt mixture incorporating coarse steel slag aggregate has improved the resilient modulus by $7 \%, 39 \%$, and $25.5 \%$ in comparison with the mixtures containing $100 \%$ of granite, $100 \%$ of steel slag aggregate, and fine steel slag aggregates, respectively. This is attributed to the better interlocking between the coarse steel slag aggregate and the fine granite aggregate. While the asphalt mixtures containing $100 \%$ of steel slag aggregate exhibited the worst resilient modulus at the two testing temperatures. On the other hand, replacing the fine granite aggregate with fine steel slag exhibited a lower resilient modulus than the control mixture. This is because fine steel slag aggregate did not perform well in terms of the interlocking. At the temperature of $40^{\circ} \mathrm{C}$, the resilient modulus of the mixtures incorporated coarse steel slag aggregate showed higher stiffness modulus than the mixtures containing $100 \%$ of granite aggregate, $100 \%$ of steel slag aggregate, and fine steel slag aggregates by $4.9 \%, 27.9 \%$, and $24.2 \%$, respectively.

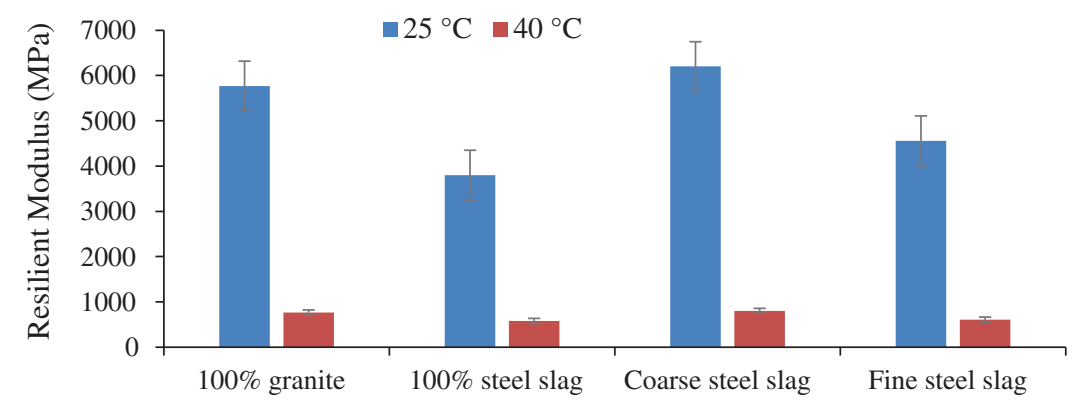

Figure 3: Resilient Modulus of the unreinforced asphalt mixtures 


\subsubsection{Moisture Susceptibility of the Unreinforced Asphalt Mixtures}

The resistance of the unreinforced asphalt mixtures to moisture sensitivity is shown in Fig. 4. As it is seen in the figure, the asphalt mixtures containing $100 \%$ of granite aggregate showed the best tensile strength ratio in comparison with the other mixtures. The asphalt mixtures incorporating steel slag as a fine and coarse aggregate showed the worst tensile strength ratio as compared to the other mixtures. This is attributed to the high porosity of the steel slag aggregates, which decreases the film thickness. As the film thickness increases, the resistance of the asphalt mixtures to the striping damage increases. Also, the asphalt mixtures incorporating fine steel slag aggregate decreased the tensile strength ratio. Thus, the asphalt mixtures composed of fine steel slag aggregates is sensitive to the moisture damage.

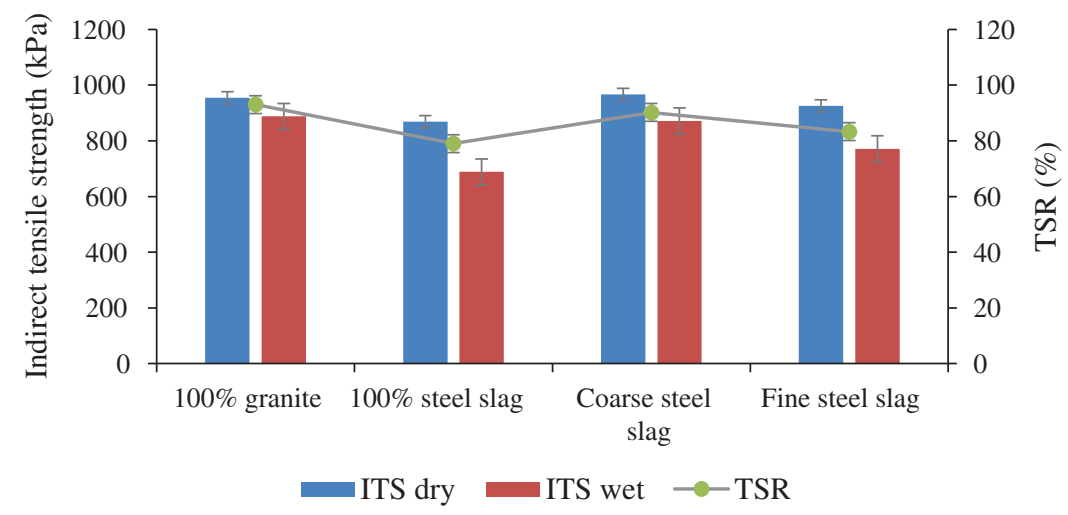

Figure 4: The Resistance of the unreinforced mixtures to moisture damage

\subsubsection{The Resistance of the Unreinforced Asphalt Mixtures to Cracking}

Fig. 5 outlines the resistance of the unreinforced asphalt mixtures to cracking. It can be seen that the cracking resistance of the mixtures incorporated coarse steel slag aggregate had improved by $13.3 \%, 38.3 \%$, and $25.3 \%$ in comparison with the mixtures incorporating $100 \%$ of granite aggregate, $100 \%$ of steel slag aggregate, and fine steel slag aggregate, respectively. While the mixtures containing 100\% steel slag aggregate showed the lowest resistance to cracking. The improvement in the cracking resistance of the asphalt mixtures containing coarse steel slag aggregate is attributed to the mechanical properties of the steel slag aggregate with respect to the hardness and angularity that produces mixtures with superior interlocking. Nonetheless, utilizing steel slag aggregate as a fine portion produces poor interlocking due to the high angularity of the fine steel slag aggregates.

\subsection{Performance Tests Results of the Reinforced Asphalt Mixtures}

This section focuses on the results of the asphalt mixtures containing coarse steel slag aggregates and reinforced with polyvinyl alcohol (PVA), acrylic, and polyester fibers.

\subsubsection{Resilient Modulus of the Reinforced Asphalt Mixtures}

Fig. 6 shows the stiffness modulus of the fiber-modified asphalt mixtures with synthetic fibers tested at $25^{\circ} \mathrm{C}$. It can be seen that the resilient modulus of the mixtures containing $0.05 \%$ (Mix1) of polyvinyl alcohol, acrylic, and polyester fibers showed a slightly higher resilient modulus in comparison with the control mixtures by $10 \%, 8.5 \%$, and $5 \%$, respectively. Besides, Mix 2 


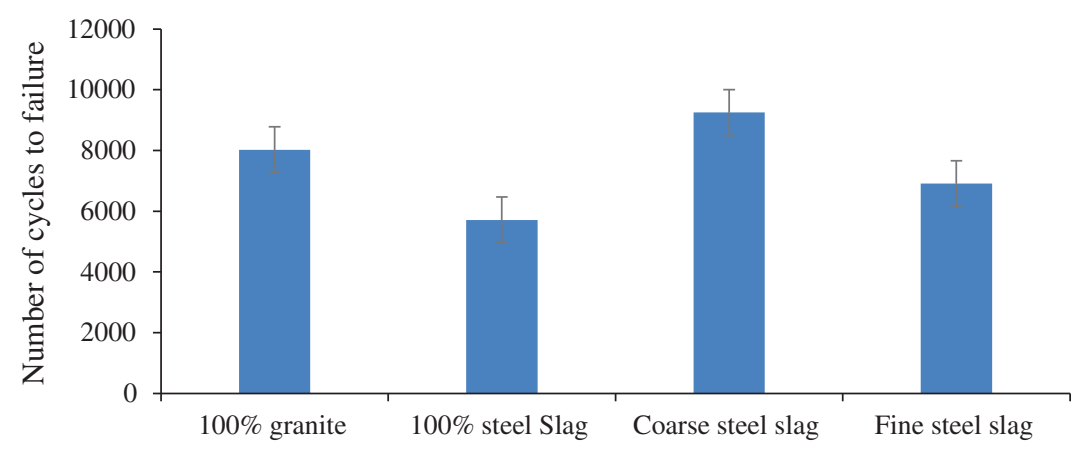

Figure 5: Resistance of the unreinforced mixtures to cracking

incorporated PVA, acrylic, and polyester fibers exhibited a slightly higher resilient modulus than Mix0 by $4.6 \%, 4 \%$, and $2 \%$, respectively. While it showed a slightly lower resilient modulus than Mix1. This is attributed to the high content of the fiber, which raises the flexible behavior of the mixtures. Moreover, the study demonstrated that Mix3 exhibited the lowest resilient modulus as compared to Mix0, Mix1, and Mix2. The lower resilient modulus of asphalt mixes incorporated a high content of synthetic fibers is attributed to the high elastic behavior. The characteristic of the reinforced mixtures in terms of the resilient modulus at the temperature of $40^{\circ} \mathrm{C}$ is shown in Fig. 7. As depicted in Fig. 7, Mixl demonstrated a slightly higher resilient modulus in comparison with Mix0. Otherwise, Mix2 and Mix3 have shown a lower value of resilient modulus. For instance, Mix3 slightly decreased the resilient modulus as compared to the unreinforced asphalt mixtures. Similar conclusions were also found in the previous studies, in which the high content of fiber increases the elastic behavior of the mixtures Mahrez et al. [26], Moreno-Navarro et al. [28], Oda et al. [47].

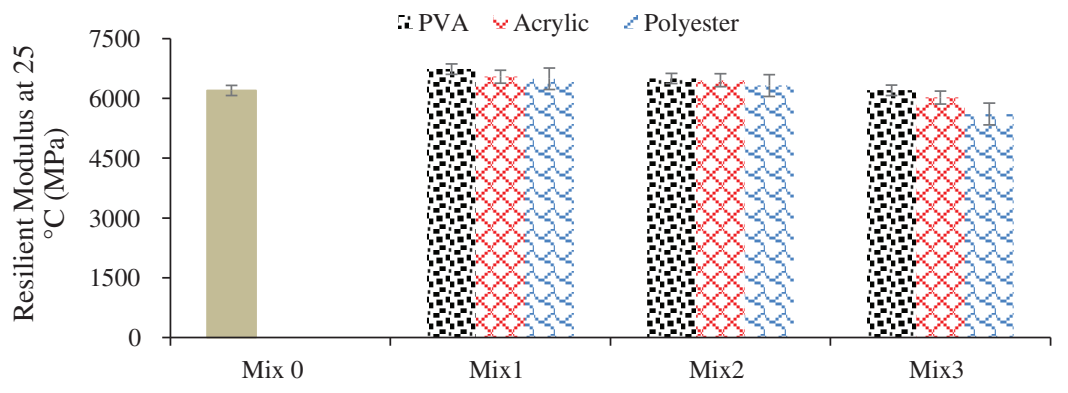

Figure 6: Resilient modulus of the reinforced mixtures at $25^{\circ} \mathrm{C}$

The T-test was conducted by means of Origin 9 software to compare the difference in the resilient modulus at the temperatures of 25 and $40^{\circ} \mathrm{C}$. The test was selected to study the difference between the groups with the assumption that the normality of the data was attained. The assumption of normality was assessed by means of the Anderson-Darling test. As seen in Tab. 4, the null hypothesis is unrejected for the groups since the p-value is not significant (higher than 0.05), which indicates that the data are normally distributed. Therefore, the t-test is suitable to examine the effect of the testing temperatures on the resilient modulus. The performed analysis was set at a significant level of 5\%. The results of the test are summarized in Tab. 5. The significant $\mathrm{p}$-value indicates that there is a significant difference among the tested groups. Thus, 


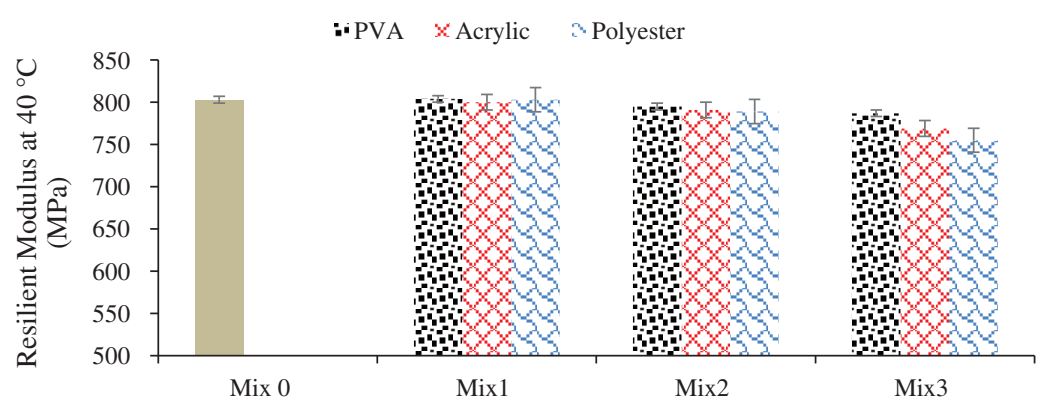

Figure 7: Resilient modulus of the reinforced mixtures at $40^{\circ} \mathrm{C}$

there is a significant effect of the testing temperature on the resilient modulus. The higher the testing temperature, the lower the resilient modulus.

Table 4: The outputs of the normality test (Anderson-Darling test)

\begin{tabular}{llll}
\hline Group & Statistic & p-value & Decision at level $(5 \%)$ \\
\hline 1 & 0.46338 & 0.23873 & Can’t reject normality \\
2 & 0.34758 & 0.45544 & Can’t reject normality \\
\hline
\end{tabular}

Table 5: The outputs of the t-test for the effect of the temperatures on the resilient modulus

\begin{tabular}{lllll}
\hline Group & $\mathrm{N}$ & Mean & SD & SEM \\
\hline 1 & 30 & 6343.13 & 298.782 & 54.54998 \\
2 & 30 & 793.233 & 18.9512 & 3.46001 \\
\hline \multicolumn{4}{l}{ T-test statistics } \\
& t Statistic & DF & p-value \\
\hline Equal variance assumed & 101.5357 & 58 & 0.000 \\
Equal variance not assumed (Welch correction) & 101.5357 & 29.2333 & 0.000 \\
\hline
\end{tabular}

\subsubsection{Moisture Susceptibility of the Reinforced Asphalt Mixtures}

The indirect tensile strength of the unconditioned samples is used as an indication of the resistance of the asphalt mixes to cracking. The high indirect tensile strength indicates that the mixtures are less susceptible to cracking. Fig. 8 presents the resistance of the mixtures to cracking, it can be seen that the reinforced asphalt mixtures with $0.05 \%$ of PVA, acrylic, and polyester fibers showed almost tensile strength values to the unreinforced asphalt mixtures. Introducing PVA, acrylic, and polyester at the percentage of $0.15 \%$ has increased the indirect tensile strength by $14.9 \%, 10.47 \%$, and $8.70 \%$, respectively. Meanwhile, the mixtures containing $0.3 \%$ of the synthetic fibers (Mix3) have improved the resistance of the mixtures to cracking by $25.26 \%$, 18\%, and $14.90 \%$, compared to the control mixture. In general, increasing the dosage of synthetic fiber has enhanced the tensile properties of the mixtures. Also, the fiber-modified asphalt mixes with 
PVA fiber exhibited the highest tensile strength than the other fibers. This is because PVA fibers possess higher tensile strength than acrylic and polyester fibers. The same behavior was observed by several previous studies, in which the reinforced asphalt mixes have higher indirect tensile strength than the reference mixes [48-51].

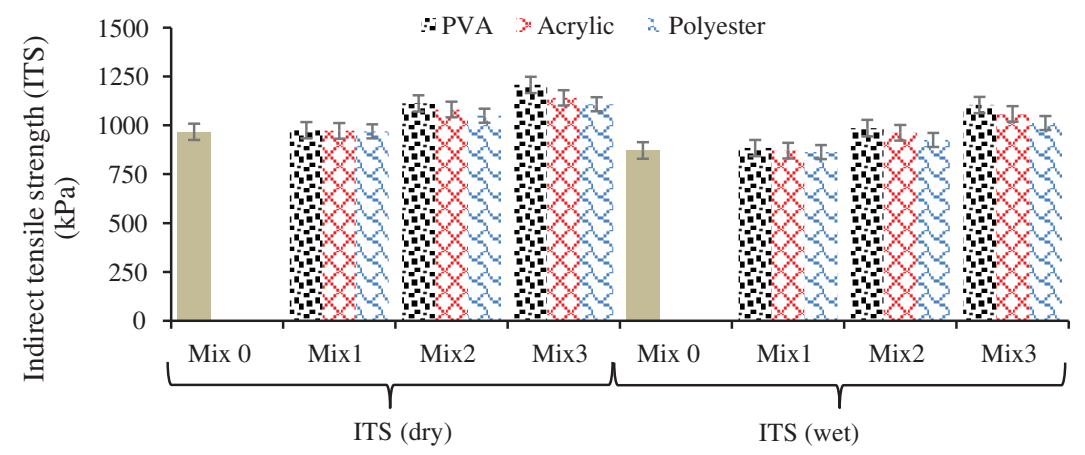

Figure 8: The unconditioned and conditioned tensile strength of the reinforced mixtures

Moisture susceptibility of the asphalt mixtures is considered as one of the main distress that influences the performance of the asphalt layer [52]. The sensitivity of the asphalt mixtures to moisture can be assessed through different experimental methods including the indirect tensile strength (ITS) test in wet conditioned. The low wet ITS indicates that the mixtures are susceptible to moisture damage. The resistance of the mixtures to moisture damage is expressed by the tensile strength ratio (TSR). The results of the asphalt mixture's resistance to moisture sensitivity are manifested in Fig. 9. The results revealed that the tensile strength ratio of the mixtures incorporated $0.05 \%$ and $0.15 \%$ of synthetics fibers was almost similar to the control mixtures. This indicates that introducing fibers to the mixtures does not affect the bonding between the binder and the aggregate. The mixtures incorporating $0.3 \%$ of synthetic fibers showed slightly higher TSR than the other mixtures. This is because the high bitumen content offers a thick film thickness as compared to the other mixtures. Fig. 10 shows the relationship between the dry indirect tensile strength and the wet indirect tensile strength. The results demonstrated a strong linear relationship between the dry and wet indirect tensile strength. The coefficient of determination for the conditioned and unconditioned indirect tensile strength was $82 \%$. Thence, it can be said that the synthetic fibers possess the ability to enhance the tensile strength of the mixes either in the dry conditioning or in the wet conditioning.

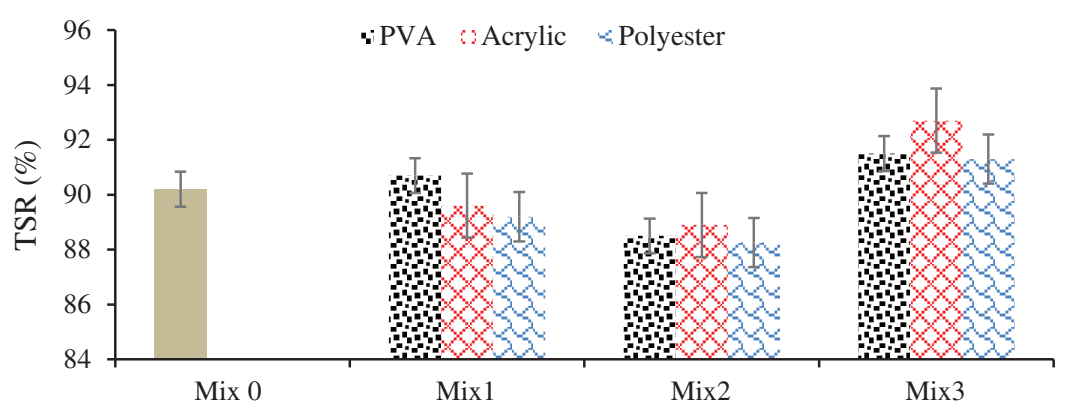

Figure 9: Tensile strength ratio of the fiber-modified asphalt mixtures 


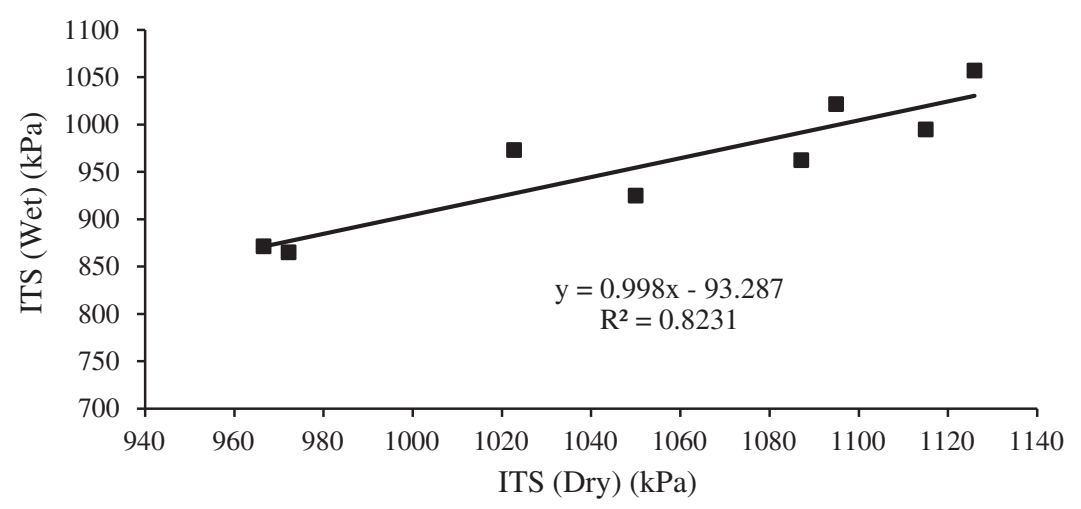

Figure 10: The relationship between ITS (Dry) and ITS (Wet)

The test of Anderson-Darling was carried out to study the distribution of the data for the effect of moisture on the indirect tensile strength (ITS) of the asphalt mixtures. Tab. 6 displays the results of the Anderson-Darling test. As reported in Tab. 6 the null hypothesis was rejected, thus the data are not normally distributed. Therefore, a nonparametric test which is Mann-Whitney was conducted to investigate the effect of moisture on the ITS. The results of the Mann-Whitney test are shown in Tab. 7. As seen in Tab. 7 subjecting the asphalt mixes to moisture has a significant effect on ITS since p-value was less than 0.05. The static indirect tensile strength is a common test used to characterize the resistance of the asphalt mixtures to cracking. Thus, the KruskalWallis test at a significant level of $5 \%$ was performed to assess the effect of adding fiber on the cracking resistance of the asphalt mixtures. Tab. 8 summarizes the Kruskal-Wallis test outputs of the fiber's influences on the indirect tensile strength. The significant $p$-value implies that the fibers have improved the resistance of the asphalt mixtures to cracking.

Table 6: The outputs of the normality test (Anderson-Darling test)

\begin{tabular}{llll}
\hline Group & Statistic & p-value & Decision at level $(5 \%)$ \\
\hline 1 & 0.72912 & 0.05115 & Can't reject normality \\
2 & 0.76147 & 0.04235 & Reject normality \\
\hline
\end{tabular}

Table 7: The outputs of the Mann-Whitney test for the effect of the moisture on the ITS

\begin{tabular}{|c|c|c|c|}
\hline Group & $\mathrm{N}$ & Mean rank & Sum rank \\
\hline 1 & 30 & 21.55 & 646.5 \\
\hline 2 & 30 & 39.45 & 1183.5 \\
\hline \multicolumn{4}{|c|}{ Mann-Whitney test statistics } \\
\hline & $\mathrm{U}$ & $\mathrm{Z}$ & p-value \\
\hline & 181.5 & 3.962 & 0.000 \\
\hline
\end{tabular}


Table 8: The outputs of the Kruskal-Wallis test for the effect of the synthetic fibers on the indirect tensile strength

\begin{tabular}{llll}
\hline PVA fiber & & & \\
\hline Group & $\mathrm{N}$ & Mean rank & Sum rank \\
\hline 1 & 3 & 3 & 9 \\
2 & 3 & 4 & 12 \\
3 & 3 & 8 & 24 \\
4 & 3 & 11 & 33 \\
\hline
\end{tabular}

Kruskal-Wallis test statistics

\begin{tabular}{lll}
\hline Chi-square & DF & p-value \\
\hline 9.461 & 3 & 0.02374 \\
\hline
\end{tabular}

Acrylic fiber

\begin{tabular}{|c|c|c|c|}
\hline Group & $\mathrm{N}$ & Mean rank & Sum rank \\
\hline 1 & 3 & 3 & \\
\hline 2 & 3 & 4 & 12 \\
\hline 3 & 3 & 8 & 24 \\
\hline 4 & 3 & 11 & 33 \\
\hline
\end{tabular}

Kruskal-Wallis test statistics

\begin{tabular}{lll}
\hline Chi-square & DF & p-value \\
\hline 9.467 & 3 & 0.0233 \\
\hline
\end{tabular}

Polyester fiber

\begin{tabular}{llll}
\hline Group & $\mathrm{N}$ & Mean rank & Sum rank \\
\hline 1 & 3 & 4 & 12 \\
2 & 3 & 3 & 9 \\
3 & 3 & 8.66667 & 26 \\
4 & 3 & 10.33333 & 31 \\
\hline
\end{tabular}

Kruskal-Wallis test statistics

\begin{tabular}{lll}
\hline Chi-square & DF & p-value \\
\hline 8.74359 & 3 & 0.0329
\end{tabular}

\subsubsection{Cracking Resistance of the Reinforced Asphalt Mixtures}

Fig. 11 demonstrates the number of cycles to failure of the reinforced asphalt mixtures. It can be seen that the higher the proportion of synthetic fibers, the higher the resistance of the asphalt mixes to cracking. Mix1 has slightly improved the resistance of the asphalt mixes to cracking as compared to Mix0. The reinforced asphalt mixtures with $0.15 \%$ of PVA, acrylic, and polyester (Mix2) fibers have enhanced the cracking resistance in comparison with Mix0 by $41.13 \%$, 
$29.87 \%$, and $18.97 \%$, respectively. Mix 3 exhibited the highest resistance to cracking in comparison with the other mixtures. In general, introducing synthetic fibers at high proportions i.e., $0.15 \%$ and $0.3 \%$ has improved the cracking resistance of the asphalt mixes. This is attributed to the high tensile strength of the synthetic fibers. In addition, the asphalt mixtures incorporating PVA fibers exhibited higher resistance to cracking than the other fiber. This is because of the high tensile strength of PVA fiber. These findings are in good agreement with the results obtained by $\mathrm{Wu}$ et al. [17], Chen et al. [18], Kim et al. [19], Wang et al. [28], Alnadish et al. [29], Oda et al. [47]. Tab. 9 presents the outcomes of the Kruskal-Wallis test for the effect of introducing synthetic fibers on the cracking resistance of asphalt mixtures. The significant $\mathrm{p}$-value reveals that reinforcing the asphalt mixtures with synthetic fibers has a positive influence in terms of improving the cracking resistance of the asphalt mixtures.

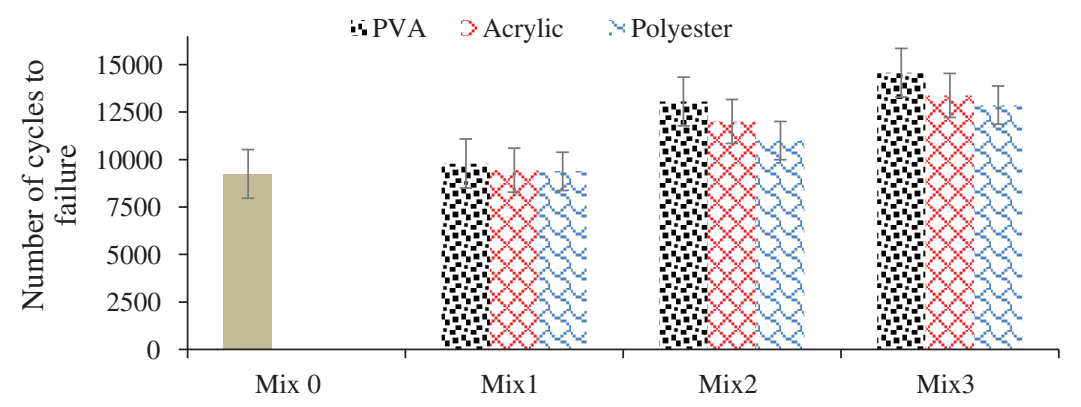

Figure 11: Resistance of the reinforced mixtures to cracking

\subsubsection{Mechanistic-Empirical Design Pavement Approach}

The decrease in the thickness of the asphalt layer contributes towards saving the cost of the construction and the transportation of the materials as well as the environmental sustainability. In this study, the mechanistic-empirical pavement design (MEPD) by means of Bisar software was employed to investigate the possibility of decreasing the thickness of the asphalt layer incorporating steel slag aggregate and synthetic fibers. The allowable number of repetitions loads to fatigue and rutting failures are calculated by Eqs. (1) and (2) [52]. The allowable number of repetitions loads to fatigue and rutting failures are determined based on the developed horizontal strain at the bottom of the surface layer and the developed vertical strain at the top of the subgrade layer, respectively. Also, Eqs. (3) and (4) are used to determine the extension in the service life of the asphalt layer and the decrease in the thickness of the asphalt layer, respectively [53]. The standard dual wheel load with a stress of $577 \mathrm{kPa}$ and a radius of $105 \mathrm{~mm}$ were chosen to study the allowable repetitions to fatigue and rutting failures. The characterizations of the assumed pavement section are summarized in Tab. 10. The pavement section consisting of four layers, which are the surface layer (hot mix asphalt), base, subbase, and subgrade. The characteristics of pavement layers (surface layer, base, subbase, and subgrade) are in accordance with the Malaysian standard specification for road works [54].

$\mathrm{Nd}=1.365 \times 10^{-9} \varepsilon v^{-4.477}$

where $\mathrm{Nd}$ is the allowable number of repetitions loads to produce a rut depth of $12.7 \mathrm{~mm}$ with. While $\varepsilon \mathrm{V}$ is the vertical strain at the top subgrade layer. 
Table 9: The outputs of Kruskal-Wallis test for the influence of the synthetic fibers on the resistance of asphalt mixtures to cracking

\begin{tabular}{|c|c|c|c|c|}
\hline \multicolumn{5}{|l|}{ PVA fiber } \\
\hline Group & $\mathrm{N}$ & Mean rank & Sum rank & \\
\hline 1 & 3 & 2.67 & 8 & \\
\hline 2 & 3 & 4.33 & 13 & \\
\hline 3 & 3 & 8 & 24 & \\
\hline 4 & 3 & 11 & 33 & \\
\hline \multicolumn{5}{|c|}{ Kruskal-Wallis test statistics } \\
\hline Chi-square & $\mathrm{DF}$ & & & $\mathrm{p}$-value \\
\hline 9.667 & 3 & & & 0.02162 \\
\hline \multicolumn{5}{|c|}{ Acrylic fiber } \\
\hline Group & $\mathrm{N}$ & Mean rank & & Sum rank \\
\hline 1 & 3 & 3.333 & & 10 \\
\hline 2 & 3 & 3.667 & & 11 \\
\hline 3 & 3 & 8 & & 24 \\
\hline 4 & 3 & 11 & & 33 \\
\hline \multicolumn{5}{|c|}{ Kruskal-Wallis test statistics } \\
\hline Chi-square & $\mathrm{DF}$ & & & $\mathrm{p}$-value \\
\hline 9.36 & 3 & & & 0.02488 \\
\hline \multicolumn{5}{|c|}{ Polyester fiber } \\
\hline Group & $\mathrm{N}$ & Mean rank & & Sum rank \\
\hline 1 & 3 & 3.333 & & 10 \\
\hline 2 & 3 & 3.667 & & 11 \\
\hline 3 & 3 & 8 & & 24 \\
\hline 4 & 3 & 11 & & 33 \\
\hline
\end{tabular}

Kruskal-Wallis test statistics

\begin{tabular}{lll}
\hline Chi-square & DF & p-value \\
\hline 9.3589 & 3 & 0.0249
\end{tabular}

The allowable number of repetitions axles to fatigue failure is calculated as follow:

$\mathrm{Nf}=1.66 \times 10^{-10} \varepsilon t^{-4.32}$

where $\mathrm{Nf}$ is the allowable number of repetitions loads until fatigue failure, while $\varepsilon \mathrm{t}$ is the horizontal tensile strain at the bottom of the asphalt layer.

$T B R=\frac{N_{f m}}{N_{f u}}$ 
where TBR is the service life of asphalt layer and $N_{f}$ is the allowable number of repetitions loads to fatigue failure, while $\mathrm{m}$ and $\mathrm{u}$ are the fiber-modified asphalt mixtures and the unreinforced mixtures.

$L T R=\frac{T u-T m}{T u}$

where LTR is the decrease in thickness of the asphalt layer, while Tu and Tm are the thickness of the unreinforced and reinforced asphalt layer.

Table 10: The proposed pavement layers (conventional pavement)

\begin{tabular}{llll}
\hline Layer & Thickness $(\mathrm{mm})$ & Resilient modulus $(\mathrm{MPa})$ & Poisson's ratio $(v)$ \\
\hline HMA & 100 & Various & 0.35 \\
Base & 250 & 350 & 0.4 \\
Sub-base & 300 & 200 & 0.4 \\
Subgrade & - & 100 & 0.45 \\
\hline
\end{tabular}

The outputs of Bisar software are presented in Tab. 11. As reported in Tab. 11, reinforcing the asphalt mixes with the synthetic fibers of PVA, acrylic, and polyester at the content of $0.05 \%$ may increase the lifespan of the asphalt layer if the thickness kept constant by 1.22, 1.13, and 1.10, respectively. The fiber-modified asphalt mixes with PVA, acrylic, and polyester at the proportion $0.15 \%$ improved the lifespan by $1.11 \%, 1.09 \%$ and $1.03 \%$ times, respectively. The fiber-modified asphalt mixtures with synthetic fibers at the dosage of $0.3 \%$ by total weight of the aggregates showed the worst service life in comparison with the other proportions. This is attributed to the low resilient modulus of the asphalt mixes containing $0.3 \%$ of synthetic fibers. The outputs of mechanistic-empirical pavement design are highly dependent on the resilient modulus value. The higher the resilient modulus, the higher the allowable repetitions loads to fatigue and rutting failures. Also, the allowable repetitions loads to fatigue failure are lower than the allowable repetitions loads to rutting failure, which indicates that the fatigue failure is the critical damage. In general, introducing synthetic fibers at the percentages of $0.05 \%$ and $0.15 \%$ has slightly increased the resilient modulus of the asphalt mixtures; however, a further increase of synthetic fibers $(0.3 \%)$ resulted in a decrease of resilient modulus value.

On the contrary, the results of the cracking tests showed that the reinforced asphalt mixtures with synthetic fibers at the content of $0.3 \%$ by weight of aggregates exhibited the highest resistance to cracking in comparison with the other proportions. Therefore, adopting the mechanisticempirical pavement design approach in determining the possibility of decreasing the thickness and the extension in the service life of the asphalt layer may introduce inaccurate analysis due to the high elastic behavior of the reinforced asphalt mixtures. It is acknowledged that the high elastic behavior of the asphalt mixtures has a low resilient modulus. Accordingly, espousing the resilient modulus in assessing the possibility of reducing the thickness of the asphalt layer may present an inexact assessment, in particular for the reinforced asphalt mixture characterized by its high elastic behavior. 
Table 11: The outputs of Bisar software

\begin{tabular}{|c|c|c|c|c|c|c|c|}
\hline Mix type & LTR & $\mathrm{h}(\mathrm{mm})$ & $\epsilon \mathrm{h}$ & $\epsilon \mathrm{V}$ & $\mathrm{Nf}$ & $\mathrm{Nd}$ & TBR \\
\hline Granite & 0 & 100 & 102.36 & 196.56 & 28592501 & 53595604 & - \\
\hline Steel slag & 0 & 100 & 97.91 & 194.19 & 34650894 & 56578889 & 1.21 \\
\hline \multicolumn{8}{|c|}{ The reinforced asphalt mixtures with synthetic fibers at the proportion of $0.05 \%$} \\
\hline \multirow{4}{*}{ PVA } & 0 & 100 & 93.51 & 191.86 & 42263812 & 59727512 & 1.22 \\
\hline & 5 & 95 & 97.83 & 197.25 & 34778379 & 52759321 & 1.00 \\
\hline & 10 & 90 & 102.14 & 202.64 & 28860630 & 46760229 & 0.83 \\
\hline & 0 & 100 & 95.21 & 192.77 & 39099526 & 58486198 & 1.13 \\
\hline \multirow[t]{3}{*}{ Acrylic } & 5 & 95 & 99.53 & 198.16 & 32284240 & 51692420 & 0.93 \\
\hline & 10 & 90 & 103.84 & 203.55 & 26874569 & 45839491 & 0.78 \\
\hline & 0 & 100 & 95.7 & 193.03 & 38240548 & 58133631 & 1.10 \\
\hline \multirow{2}{*}{ Polyester } & 5 & 95 & 100.02 & 198.42 & 31605345 & 51389254 & 0.91 \\
\hline & 10 & 90 & 104.33 & 203.81 & 26332629 & 45577746 & 0.76 \\
\hline
\end{tabular}

The reinforced asphalt mixtures with synthetic fibers at the proportion of $0.15 \%$

\begin{tabular}{llllllll}
\hline \multirow{3}{*}{ PVA } & 0 & 100 & 95.63 & 192.99 & 38366327 & 58185699 & 1.11 \\
& 5 & 95 & 99.95 & 198.38 & 31704805 & 51434030 & 0.91 \\
\multirow{3}{*}{ Acrylic } & 10 & 90 & 104.26 & 203.77 & 26412061 & 45616408 & 0.76 \\
& 0 & 100 & 96.05 & 193.21 & 37649986 & 57887086 & 1.09 \\
& 5 & 95 & 100.36 & 198.6 & 31138124 & 51177218 & 0.90 \\
Polyester & 0 & 90 & 104.68 & 203.99 & 25959317 & 45394651 & 0.75 \\
& 10 & 100 & 97.26 & 193.85 & 35669520 & 57034192 & 1.03 \\
& 10 & 90 & 101.57 & 199.24 & 29568420 & 50443472 & 0.85 \\
\hline
\end{tabular}

The reinforced asphalt mixtures with synthetic fibers at the proportion of $0.3 \%$

\begin{tabular}{llllllll}
\hline \multirow{3}{*}{ PVA } & 0 & 100 & 98.329 & 194.42 & 34018830 & 56290328 & 0.98 \\
& 5 & 95 & 102.64 & 199.81 & 28256612 & 49803228 & 0.82 \\
& 10 & 90 & 106.96 & 205.20 & 23650547 & 44207597 & 0.68 \\
Acrylic & 0 & 100 & 99.99 & 195.30 & 31640698 & 55160034 & 0.91 \\
& 5 & 95 & 104.31 & 200.69 & 26360864 & 48829849 & 0.76 \\
& 10 & 90 & 108.63 & 206.08 & 22125265 & 43366014 & 0.64 \\
Polyester & 0 & 100 & 101.18 & 195.93 & 30063246 & 54367939 & 0.87 \\
& 5 & 95 & 105.50 & 201.32 & 25099399 & 48147328 & 0.72 \\
& 10 & 90 & 109.82 & 206.72 & 21107353 & 42775587 & 0.71 \\
\hline
\end{tabular}

In this study, the possibility of reducing the thickness of the reinforced asphalt layer was evaluated using the results of the cracking tests (static and dynamic (repeated) indirect tensile strength). It is recognized that the results of the indirect tensile strength test are in a strong relationship with the results of the other cracking tests. The higher the indirect tensile strength, the higher the resistance to cracking. Therefore, the results of the indirect tensile strength and the repeated indirect tensile strength were chosen to investigate the possibility of decreasing the thickness of the reinforced asphalt layer because the outputs of Bisar software showed that the 
critical damage was fatigue cracking. Tab. 12 summarizes the results of the static and dynamic (repeated) indirect tensile strength. As seen in Tab. 12, the resistance of the asphalt mixtures to cracking by the static mode is critical, since it has a lower improvement rate than the dynamic indirect tensile strength. The rate of augmentation in the resistance of the reinforced mixture to cracking corresponds to the rate in reducing the thickness of the asphalt layer. Tab. 12 shows that introducing synthetic fiber at the proportion of $0.05 \%$ has no effect in terms of reducing the thickness of the asphalt layer. Whereas adding synthetic fibers at the percentage of $0.15 \%$ has minimized the thickness of the asphalt layer by $14.9 \%, 11.80 \%$, and $8.70 \%$ for the asphalt mixtures incorporated with PVA, acrylic, and polyester, respectively. Also, the asphalt mixtures containing $0.15 \%$ by weight of the aggregates of PVA, acrylic, and polyester may increase the lifespan of the asphalt layer if the thickness kept constant by $14.9 \%, 11.8 \%$, and $8.70 \%$, respectively. Moreover, reinforcing the asphalt mixtures with PVA, acrylic, and polyester fibers at the proportion of $0.3 \%$ have increased the resistance of the mixtures to cracking by $25.26 \%, 18 \%$, and $14.90 \%$, respectively.

Modifying the asphalt mixtures with the synthetic fibers of PVA, acrylic, and polyester at the content of $0.15 \%$ by weight of the aggregates may increase the cost of the production by about $10.9 \%, 7.6 \%$, and $5.4 \%$, respectively. On the other hand, reinforcing the asphalt mixes with the synthetic fibers of PVA, acrylic, and polyester at the dosage of $0.3 \%$ by weight of the aggregates may raise the cost of production by about $22 \%, 15 \%$, and $11 \%$ per ton, respectively. Therefore, the fiber-modified asphalt mixtures with the synthetic fibers at the content of $0.15 \%$ by weight of the aggregates are the best in economic terms.

Table 12: The outputs of the cracking tests

\begin{tabular}{llllll}
\hline Mix type & $\begin{array}{l}\text { Type of } \\
\text { fiber }\end{array}$ & ITS $(\mathrm{MPa})$ & $\begin{array}{l}\text { Cycles to } \\
\text { failure }\end{array}$ & $\begin{array}{l}\text { ITS } \\
\text { improvement } \\
\text { rate }(\%)\end{array}$ & $\begin{array}{l}\text { Cycles } \\
\text { improvement } \\
\text { rate }(\%)\end{array}$ \\
\hline Mix0 & - & 0.966 & 9250 & - & - \\
Mix1 & PVA & 0.975 & 9791 & 0.94 & 5.85 \\
& Acrylic & 0.972 & 9440 & 0.62 & 2.05 \\
& Polyester & 0.969 & 9389 & 0.30 & 1.50 \\
& PVA & 1.11 & 13055 & 14.90 & 41.13 \\
Mix2 & & & & & \\
& Acrylic & 1.08 & 12013 & 11.80 & 18.97 \\
& Polyester & 1.05 & 11005 & 8.70 & 57.63 \\
\multirow{3}{*}{ Mix3 } & PVA & 1.21 & 14581 & 25.26 & 44.74 \\
& & & & & 39.17 \\
\hline
\end{tabular}

\section{Conclusions}

Based on the results of this study, the following conclusions were made:

- The asphalt mixes incorporated coarse steel slag aggregate exhibited the best performance in comparison with the other substitutions in terms of the resilient modulus and fatigue 
resistance. While the asphalt mixes incorporating 100\% of steel slag aggregates exhibited the worst performance.

- Reinforcing the asphalt mixtures with synthetic fiber at the content of $0.05 \%$ have shown an almost comparable performance to the unreinforced asphalt mixes. Moreover, introducing synthetic fiber at the dosages of $0.15 \%$ and $0.3 \%$ exhibited the best resistance to cracking as compared to the other mixtures.

- The outputs of mechanistic-empirical pavement design demonstrated that the resilient modulus of the asphalt mixtures has a direct influence on the allowable repetitions loads to fatigue and rutting damage. The higher the resilient modulus, the higher the allowable repetitions loads. Thus, reinforcing the asphalt mixtures with synthetic fibers at the content of $0.3 \%$ showed lower repetitions loads as compared to the other mixtures. This is attributed to the high elastic behavior of the reinforced asphalt mixtures.

- The results of cracking tests showed that the resistance of the asphalt mixes to cracking increases with the increase of fiber content. Therefore, assessing the possibility of decreasing the thickness and extending the lifespan of the asphalt layer based on the laboratory tests may produce a better evaluation and understanding than the mechanistic-empirical pavement design, in particular for the asphalt mixture characterized by its high elastic behavior.

- The fiber-modified asphalt mixtures with the synthetic fibers of PVA, acrylic, and polyester at the proportion of $0.15 \%$ possess the possibility to decrease the thickness of asphalt layer by about $14.9 \%, 11.80 \%$, and $8.70 \%$, respectively. Therefore, adding the synthetic fibers at the content of $0.15 \%$ by weight of the aggregates is the best in economic terms.

Acknowledgement: The authors would like to acknowledge Universiti Tun Hussein Onn Malaysia and Universiti Tenaga Nasional for technical and financial support to this research.

Funding Statement: This work was supported by Universiti Tenaga Nasional (UNITEN) through BOLD Refresh Publication Fund 2021 under Grant J5100D4103 - BOLDREFRESH2025CENTRE OF EXCELLENCE.

Conflicts of Interest: The authors declare that they have no conflicts of interest to report regarding the present study.

\section{References}

[1] A. Behnood and M. Ameri, "Experimental investigation of stone matrix asphalt mixtures containing steel slag," Scientia Iranica, vol. 19, no. 5, pp. 1214-1219, 2012.

[2] H. Ziari, S. Nowbakht, S. Rezaei and A. Mahboob, "Laboratory investigation of fatigue characteristics of asphalt mixtures with steel slag aggregates," Advances in Materials Science \& Engineering, vol. 2015, no. 1583 , pp. $1-5,2015$.

[3] M. Pasetto and N. Baldo, "Experimental evaluation of high performance base course and road base asphalt concrete with electric arc furnace steel slags," Journal of Hazardous Materials, vol. 181, no. 1-3, pp. 938-948, 2010.

[4] M. Pasetto and N. Baldo, "Performance comparative analysis of stone mastic asphalts with electric arc furnace steel slag: A laboratory evaluation," Materials \& Structures, vol. 45, no. 3, pp. 411-424, 2012.

[5] P. Ahmedzade and B. Sengoz, "Evaluation of steel slag coarse aggregate in hot mix asphalt concrete," Journal of Hazardous Materials, vol. 165, no. 1-3, pp. 300-305, 2009. 
[6] M. Arabani and A. R. Azarhoosh, "The effect of recycled concrete aggregate and steel slag on the dynamic properties of asphalt mixtures," Construction \& Building Materials, vol. 35, no. 9, pp. 1-7, 2012.

[7] M. Kavussi, J. Qazizadeh and A. Hassani, "Fatigue behavior analysis of asphalt mixes containing electric arc furnace steel slag," Journal of Rehabilitation in Civil Engineering, vol. 3, no. 1, pp. 74-86, 2015.

[8] H. Wen, S. Wu and S. Bhusal, "Performance evaluation of asphalt mixes containing steel slag aggregate as a measure to resist studded tire wear," Journal of Materials in Civil Engineering, vol. 28, no. 5, pp. 4015191, 2016.

[9] M. Ameri, S. Hesami and H. Goli, "Laboratory evaluation of warm mix asphalt mixtures containing electric arc furnace steel slag," Construction \& Building materials, vol. 49, no. 1, pp. 611-617, 2013.

[10] S. Hesami, M. Ameri, H. Goli and A. Akbari, "Laboratory investigation of moisture susceptibility of warm-mix asphalt mixtures containing steel slag aggregates," International Journal of Pavement Engineering, vol. 16, no. 8, pp. 745-759, 2015.

[11] M. F. Ali and M. N. Siddiqui, "Changes in asphalt chemistry and durability during oxidation and polymer modification," Petroleum Science \& Technology, vol. 19, no. 9-10, pp. 1229-1249, 2001.

[12] M. S. Cortizo, D. O. Larsen, H. Bianchetto and J. L. Alessandrini, "Effect of the thermal degradation of SBS copolymers during the ageing of modified asphalts," Polymer Degradation \& Stability, vol. 86, no. 2, pp. 275-282, 2004.

[13] C. Yan, W. Huang, M. Zheng, Y. Zhang and P. Lin, "Influence of ageing on high content polymer modified asphalt mixture stripping, cracking and rutting performances," Road Materials \& Pavement Design, vol. 20, no. 11, pp. 1-18, 2020.

[14] S. Tapkın, "The effect of polypropylene fibers on asphalt performance," Building \& Environment, vol. 43, no. 6, pp. 1065-1071, 2008.

[15] S. M. Abtahi, R. Khodadahi, S. M. Hejazi and E. Tavakkol, "A feasibility study on the use of polypropilene fibers as a modifier in asphalt-concretes made from steel slag," in 4th National Conf. on Bitumen and Asphalt, Tehran, Iran, 2008.

[16] L. M. G. Klinsky, K. E. Kaloush, V. C. Faria and V. S. S. Bardini, "Performance characteristics of fiber modified hot mix asphalt," Construction \& Building Materials, vol. 176, no. 2, pp. 747-752, 2018.

[17] S. Wu, Q. Ye and N. Li, "Investigation of rheological and fatigue properties of asphalt mixtures containing polyester fibers," Construction \& Building Materials, vol. 22, no. 10, pp. 2111-2115, 2008.

[18] H. Chen, Q. Xu, S. Chen and Z. Zhang, "Evaluation and design of fiber-reinforced asphalt mixtures," Materials \& Design, vol. 30, no. 7, pp. 2595-2603, 2009.

[19] M.-J. Kim, S. Kim, D.-Y. Yoo and H.-O. Shin, "Enhancing mechanical properties of asphalt concrete using synthetic fibers," Construction \& Building Materials, vol. 178, no. 2, pp. 233-243, 2018.

[20] S. G. Jahromi and A. Khodaii, "Carbon fiber reinforced asphalt concrete," Arabian Journal for Science \& Engineering (Springer Science \& Business Media), vol. 33, pp. 355-364, 2008.

[21] N. Morova, "Investigation of usability of basalt fibers in hot mix asphalt concrete," Construction \& Building Materials, vol. 47, no. 2012, pp. 175-180, 2013.

[22] R. Xiong, J. Fang, A. Xu, B. Guan and Z. Liu, "Laboratory investigation on the brucite fiber reinforced asphalt binder and asphalt concrete," Construction \& Building Materials, vol. 83, no. 2, pp. 44-52, 2015.

[23] Q. Guo, L. Li, Y. Cheng, Y. Jiao and C. Xu, "Laboratory evaluation on performance of diatomite and glass fiber compound modified asphalt mixture," Materials \& Design, vol. 66, no. 2, pp. 51-59, 2015.

[24] M. Fakhri and S. A. Hosseini, "Laboratory evaluation of rutting and moisture damage resistance of glass fiber modified warm mix asphalt incorporating high RAP proportion," Construction \& Building Materials, vol. 134, no. 3, pp. 626-640, 2017.

[25] S. M. Abtahi, M. Sheikhzadeh and S. M. Hejazi, "Fiber-reinforced asphalt-concrete-a review," Construction \& Building Materials, vol. 24, no. 6, pp. 871-877, 2010. 
[26] S. J. Lee, J. P. Rust, H. Hamouda, Y. R. Kim and R. H. Borden, "Fatigue cracking resistance of fiber-reinforced asphalt concrete," Textile Research Journal, vol. 75, no. 2, pp. 123-128, 2005.

[27] F. Moreno-Navarro, M. Sol-Sánchez, E. Tomás-Fortún and M. C. Rubio-Gámez, "High-modulus asphalt mixtures modified with acrylic fibers for their use in pavements under severe climate conditions," Journal of Cold Regions Engineering, vol. 30, no. 4, pp. 4016003, 2016.

[28] H. Wang, Z. Yang, S. Zhan, L. Ding and K. Jin, "Fatigue performance and model of polyacrylonitrile fiber reinforced asphalt mixture," Applied Sciences, vol. 8, no. 10, pp. 1818, 2018.

[29] A. Alnadish and Y. Aman, "A study on the economic using of steel slag aggregate in asphalt mixtures reinforced by aramid fiber," ARPN Journal of Engineering \& Applied Sciences, vol. 13, no. 1, pp. 276-292, 2018.

[30] A. Alnadish and Y. Aman, "Mechanistic approach for reducing the thickness of asphalt layer incorporating steel slag aggregate," Civil Engineering Journal, vol. 4, no. 2, pp. 334-345, 2018.

[31] A. M. Alnadish, M. Y. Aman, H. Y. B. Katman and M. R. Ibrahim, "Laboratory assessment of the performance and elastic behavior of asphalt mixtures containing steel slag aggregate and synthetic fibers," International Journal of Pavement Research \& Technology, vol. 14, no. 4, pp. 473-481, 2021.

[32] A. M. Alnadish, M. Y. Aman, H. Y. B. Katman and M. R. Ibrahim, "Influence of the long-term oven aging on the performance of the reinforced asphalt mixtures," Coatings, vol. 10, no. 10, pp. 953, 2020.

[33] ASTM, Standard Test Method for Penetration of Bituminous Materials. Conshohocken, PA, USA: American Society for Testing and Materials, West, 2013.

[34] ASTM, Standard Test Method for Softening Point of Bitumen (Ring-and-Ball Apparatus). Conshohocken, PA, USA: American Society for Testing and Materials, West, 2014.

[35] ASTM, Standard Test Method for Standard Test Method for Ductility of Bituminous Materials. Conshohocken, PA, USA: American Society for Testing and Materials, West, 2007.

[36] ASTM, Standard Test Method for Viscosity Determination of Asphalt at Elevated Temperatures using a Rotational Viscometer. Conshohocken, PA, USA: American Society for Testing and Materials, West, 2015.

[37] ASTM, Standard Viscosity-Temperature Chart for Asphalts. Conshohocken, PA, USA: American Society for Testing and Materials, West, 2009.

[38] ASTM, Resistance to Abrasion of Small-Size Coarse Aggregate by use of the Los Angeles Machine. Conshohocken, PA, USA: American Society for Testing and Materials, West, 1989.

[39] IS, Methods of Test for Aggregates, Bureau of Indian Standards. New Delhi: Manak Bhavan, 1963.

[40] ASTM, Standard Test Method for Relative Density (Specific Gravity) and Absorption of Coarse Aggregate. Conshohocken, PA, USA: American Society for Testing and Materials, West, 2015.

[41] ASTM, Standard Test Method for Flat Particles, Elongated Particles, or Flat and Elongated Particles in Coarse Aggregate. Conshohocken, PA, USA: American Society for Testing and Materials, West, 2010.

[42] ASTM, Standard Test Method for Determining the Percentage of Fractured Particles in Coarse Aggregate. Conshohocken, PA, USA: American Society for Testing and Materials, West, 2013.

[43] R. J. Cominsky, G. A. Huber, T. W. Kennedy and M. Anderson, The Superpave Mix Design Manual for New Construction and Overlays. Washington, DC: Strategic Highway Research Program, 1994.

[44] ASTM, Standard Test Method for Determining the Resilient Modulus of Bituminous Mixtures by Indirect Tension Test. Conshohocken, PA, USA: American Society for Testing and Materials, West, 2011.

[45] T. Aashto, Standard Method of Test for Resistance of Compacted Asphalt Mixtures to Moisture-Induced Damage. Washington, DC: American Association of State and Highway Transportation Officials, 2007.

[46] E. N. EN, "Bituminous mixtures-test methods for hot mix asphalt-part 24: Resistance to fatigue," European Standard, United Kingdom, 2012.

[47] S. Oda, J. L. Fernandes Jr Jr and J. S. Ildefonso, "Analysis of use of natural fibers and asphalt rubber binder in discontinuous asphalt mixtures," Construction \& Building Materials, vol. 26, no. 1, pp. 13-20, 2012. 
[48] H. Ziari and A. Moniri, "Laboratory evaluation of the effect of synthetic polyolefin-glass fibers on performance properties of hot mix asphalt," Construction \& Building Materials, vol. 213, no. 15, pp. 459-468, 2019.

[49] Z. Wu, C. Zhang, P. Xiao, B. Li and A. Kang, "Performance characterization of hot mix asphalt with high RAP content and basalt fiber," Materials, vol. 13, no. 14, pp. 3145, 2020.

[50] J. Stempihar, M. I. Souliman and K. E. Kaloush, "Fiber-reinforced asphalt concrete as sustainable paving material for airfields," Transportation Research Record, vol. 2266, no. 1, pp. 60-68, 2012.

[51] X. Chen and B. Huang, "Evaluation of moisture damage in hot mix asphalt using simple performance and superpave indirect tensile tests," Construction \& Building Materials, vol. 22, no. 9, pp. 1950-1962, 2008.

[52] A. Mokhtari and F. M. Nejad, "Mechanistic approach for fiber and polymer modified SMA mixtures," Construction \& Building Materials, vol. 36, no. 4, pp. 381-390, 2012.

[53] A. I. Al-Hadidy and Y. Tan, "Mechanistic analysis of ST and SBS-modified flexible pavements," Construction \& Building Materials, vol. 23, no. 8, pp. 2941-2950, 2009.

[54] P. W. D. Malaysia, Standard Specification for Road Works, Section 4, Flexible Pavement,Kuala Lumpur: Jabatan Kerja Raya Malaysia, 2008. 